\title{
Por uma sociologia dos etnométodos para compreender o mundo da educação: contribuições de Alain Coulon
}

\author{
Marilia Pontes Sposito' \\ Belmira Oliveira Bueno' \\ Ana Maria Freitas Teixeirall!
}

I- Universidade de São Paulo, São

Paulo, SP, Brasil.

Contatos: sposito@usp.br;

bbueno@usp.br

III- Universidade Federal do Recôncavo

da Bahia, Santo Amaro, BA, Brasil.

Contato: ana.f.teixeira@hotmail.br

\section{Resumo}

0 texto apresenta entrevista com Alain Coulon, pesquisador francês responsável pelo desenvolvimento dos estudos em etnometodologia aplicados à educação na sociologia francesa. 0 caráter inovador de sua linha de investigação, inspirada nas formulações de Garfınkel e Cicourel, permitiu um conjunto de pesquisas sobre os estudantes universitários em momento de transformação do ensino superior francês. A partir dos anos 1980, a universidade francesa sofreu processo intenso de abertura de oportunidades de acesso, reunindo um público amplo e heterogêneo de estudantes que demandava novas abordagens para a compreensão de sua experiência acadêmica. Esse universo de investigação eleito por Alain Coulon constituiu o material empírico que permitiu ao autor a produção não só de novas metodologias de pesquisa como a formulação de novas categorias de análise, elucidativas dessas novas realidades. Dentre elas destaca-se a ideia de afiliação. Sua influência teórica disseminou-se por vários países, mediante tradução de seus principais trabalhos para o alemão, inglês, japonês, dentre outros idiomas. No Brasil, seu diálogo com pesquisadores ofereceu apoio à criação de observatórios da vida estudantil em diferentes universidades, bem como ações sistematizadas de afiliação e sucesso acadêmico, revelando-se um caminho promissor para a pesquisa. Diante da expansão recente do ensino superior brasileiro, sobretudo a partir das políticas afirmativas, os desafios para a pesquisa são significativos e podem ser enfrentados de maneira mais densa se forem fortalecidos os diálogos com pesquisadores que se voltaram para a compreensão dessas novas realidades, tendo em vista a superação das desigualdades estruturais e persistentes que configuram historicamente a universidade.

\section{Palavras-chave}

Etnometodologia - Estudantes universitários - Afiliação Sociologia francesa. 


\title{
For a sociology of ethnomethods to understand the world of education: Alain Coulon's contributions
}

\author{
Marilia Pontes Sposito' \\ Belmira Oliveira Bueno' \\ Ana Maria Freitas Teixeirall!
}

I- Universidade de São Paulo, São Paulo, SP, Brasil.

Contact: sposito@usp.br

bbueno@usp.br

III- Universidade Federal do Recôncavo

da Bahia, Santo Amaro, BA, Brasil.

Contact: ana.f.teixeira@hotmail.br

\begin{abstract}
The paper results from an interview with Alain Coulon, French researcher responsible for the development of the studies in ethnomethodology applied to education within French Sociology. The innovative character of his line of investigation, inspired by the ideas of Garfinkel and Cicourel, has fostered a host of studies about university students, in a time of transformations in the French higher education system. Since the 1980s French universities have gone through intense expansion of opportunities in their access, and have received a wide and heterogeneous population of students, which in turn have demanded new approaches to understand their academic experience. The field of investigation chosen by Alain Coulon was the empirical material that allowed him not only to put forward new research methodologies, but also to formulate new categories of analysis in the effort to clarify these new phenomena. Among them, the concept of affiliation has taken special relevance. His theoretical influence has reached several countries after his main works were translated into many languages including German, English, and Japanese. In Brazil, his dialogue with local researchers gave support to the creation of Observatories of student life in several universities, as well as to systematized initiatives of affiliation and academic success, which turned out to be a promising direction for future studies. The recent growth experienced by the Brazilian higher education system has given rise to significant research challenges, and these will be dealt with more forcefully through the dialogue with researchers that are attempting to understand this new reality, with the purpose of overcoming the persistent and structural inequalities that have historically shaped Brazilian university.
\end{abstract}

\section{Keywords}

Ethnomethodology - University students - Affiliation - French Sociology. 


\section{Apresentação}

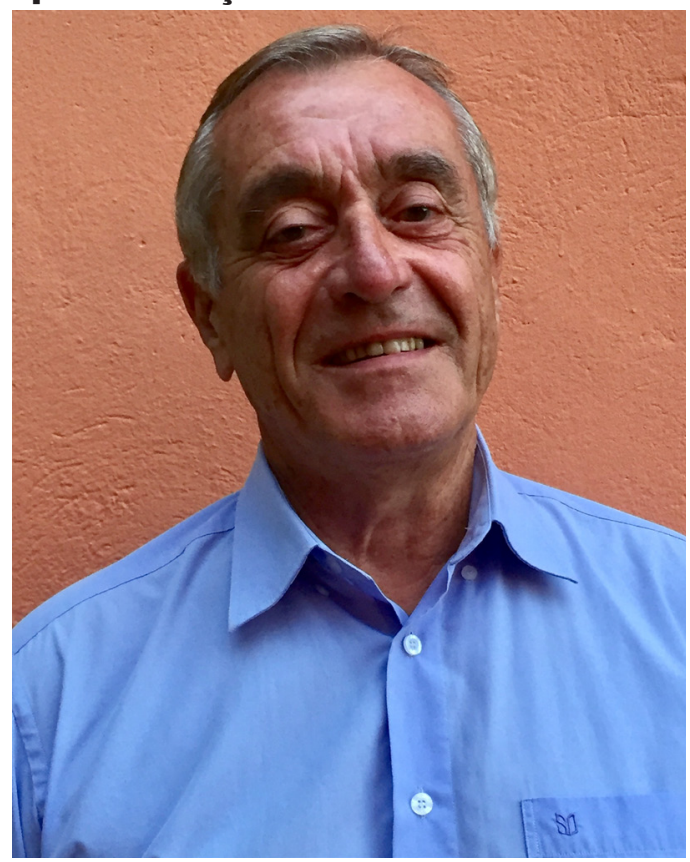

Fonte: arquivos pessoais do entrevistado.

Herdeiro da rica tradição sociológica francesa que se iniciou nos anos 1960, Alain Coulon tem seu nome fortemente associado entre nós à etnometodologia, tendo sempre se dedicado ao tema da universidade e seu público. A associação maior que dele se faz com a etnometodologia se deve, principalmente, à tradução e publicação no Brasil, em meados da década de 1990, de três livros nos quais Coulon trata de questões teóricas e metodológicas da pesquisa sociológica na educação. Num deles, ele examina as origens, os métodos e a herança deixada pela Escola de Chicago (COULON, 1995a); nos outros dois aborda a etnometodologia e os impactos dessa teoria e das metodologias de pesquisa que defende no âmbito das ciências sociais (COULON, 1995c) e seu uso na educação (COULON, 1995b) ${ }^{1}$.

Alain Coulon foi professor de ciências da educação na Universidade de Paris 8, uma instituição inovadora em suas origens, onde

1- A segunda edição de Etnometodologia e educação foi publicada em outubro de 2017 pela editora Cortez (COULON, 2017), com prefácio de Marilia Pontes Sposito e tradução de Ana Teixeira. trabalhou por trinta anos, assumindo diferentes responsabilidades acadêmicas, tais como diretor da Faculdade de Educação. Além de conhecedor das entrelinhas das salas de aula da universidade, ele acumulou, ao longo de sua dinâmica e produtiva carreira, uma importante experiência na gestão do ensino superior na França, atuando como diretor da Estratégia do Ensino Superior e da Inserção Profissional, o que lhe permitiu ampliar e aprofundar a compreensão sobre o fenômeno da transição entre o ensino médio e a universidade, bem como evidenciar a importância de uma pedagogia da afiliação voltada, sobretudo, para os novos universitários. Como consultor internacional, tem colocado sua experiência a serviço da implantação de programas voltados à estruturação das instituições de ensino superior em países do norte da África. Ao longo dos últimos vinte anos, tem estreitado sua parceria com a universidade brasileira mediante a realização de pesquisas, conferências, assessorias, que têm permitido uma aproximação estreita com a realidade do ensino superior no Brasil.

Sua formação se deu em meio à efervescência de ideias que marcaram o contexto acadêmico de seu país nos anos 1960, tendo sido aluno de Jean Duvignaud, Georges Lapassade, Roger Establet, Lacan, dentre outros mestres que ousadamente perscrutaram novos horizontes para a investigação nas ciências humanas. Por meio deles, Alain Coulon enveredou por temas e metodologias até então pouco conhecidos, ou de desinteresse por grande parte dos sociólogos daquele período. Tal é o caso da questão da universidade e seu público, tema que ele abraçou desde os primeiros anos de sua carreira, e da abordagem etnometodológica, que provocou intensos debates e grandes reviravoltas no campo das ciências sociais, em vários países (COULON, 1995c, p. 7).

Em sua trajetória Coulon mostra interesse precoce em estudar a temática da universidade e seu público, antes mesmo de sua descoberta da etnometodologia. Em 
sua primeira tese acadêmica, ele examinou a reforma do ensino superior na Argélia, e suas pesquisas subsequentes permitiram um grande acúmulo de dados estatísticos sobre o desempenho acadêmico dos estudantes. Diante das transformações operadas no acesso ao ensino superior na França, realidade presente na sociedade brasileira contemporânea, Alain Coulon observa a formação de um novo público estudantil, heterogêneo e distante do ethos prevalecente na cultura acadêmica. As maiores oportunidades de acesso produziram novos problemas e desafios, traduzidos nos elevados índices de fracasso e do abandono de cursos.

Os parâmetros dominantes no interior da sociologia tornaram-se insuficientes para aprofundar a análise sobre esse novo quadro do ensino superior. Nesse momento, em meados dos anos 1980, o pesquisador encontra-se com a etnometodologia, vendo nela uma forte inspiração para o desenvolvimento de novas pesquisas que culminam com sua tese de doutorado, defendida em 1990 (COULON, 1990). 0 acompanhamento dos ingressantes e a utilização de estratégias diversas de levantamento de dados permitiram construir novas categorias de análise que certamente dão conta de uma realidade dinâmica e processual que caracteriza o aprendizado do ofício de estudante: afiliação, membro e regra.

A afiliação é, para Coulon, uma categoria que poderá completar a noção de habitus desenvolvida por Pierre Bourdieu (BOURDIEU, 2000; 1980). Recorre, para tanto, às análises que marcaram a ruptura com a noção de membro, cunhada pelo funcionalismo parsoniano, e volta-se às formulações de Howard Becker (1985) e David Matza (1969) para situar sua perspectiva e o modo como ela opera no estudo sobre os estudantes universitários. A categoria regra está estreitamente ligada à afiliação uma vez que os processos que a possibilitam estão vinculados à capacidade dos atores de seguir as regras dos novos universos a que se integram.

Além das contribuições na produção de conhecimentos sobre os novos públicos estudantis, seus trabalhos posteriores reúnem impor- tantes intervenções e propostas para a atividade acadêmica de estudantes universitários. A experiência do diário que opera no desenvolvimento da escrita e a análise documental certamente amplia as possibilidades de compreensão desse intenso trabalho que os novos estudantes do ensino superior podem desenvolver e reverter trajetórias condenadas ao fracasso ou à evasão.

Sua adesão à etnometodologia se deu tão logo Coulon entrou em contato com os trabalhos dos pioneiros dessa abordagem, em particular, os textos de Harold Garfinkel reunidos em Studies in Ethnometodology, publicado originalmente em 1967. Quando esses trabalhos começaram a chegar à França, nos anos 1980, Alain Coulon sentiu-se imediatamente atraído pela proposta teórica e metodológica que portavam, sobretudo, pela ideia de investigar a racionalidade que orienta os atores sociais em suas ações na vida cotidiana. Isso lhe abria caminhos para a compreensão das práticas empregadas no senso comum e os sentidos que os indivíduos atribuem a suas ações, sejam elas triviais ou eruditas. Ao tratar da reviravolta etnometodológica em seu livro Etnometodologia e Educação, ele esclarece que

Essa metodologia leiga - constituída pelo conjunto do que vamos designar por etnométodos - utilizada, de forma banal, mas engenhosa, pelos membros de uma sociedade ou grupo para viverem juntos, constitui o corpus da pesquisa etnometodológica. (COULON, 1995b, p. 15).

Para o sociólogo, um dos méritos dessa abordagem reside na possibilidade que oferece para se estabelecer uma relação entre os níveis micro e macro na análise sociológica, algo que não era compartilhado pela maioria dos sociólogos de tradição clássica. Tal perspectiva se fazia possível mediante a imersão do pesquisador na vida cotidiana dos atores sociais, conforme propunha Garfinkel (1984). Porém, abraçar essa perspectiva significava enfrentar a recusa ao novo e ao inusitado por parte de 
seus pares, similarmente ao que havia ocorrido com os antropólogos que, em décadas passadas, adotaram a etnografia como forma privilegiada para o estudo de grupos apartados das sociedades urbanizadas. Talvez, essa similaridade se deva, primeiramente, ao fato de as duas abordagens romperem com os padrões estabelecidos em suas disciplinas de origem - a sociologia num caso, e a antropologia no outro - além de guardarem entre si vários pontos comuns, que se explicitam pelo próprio radical ethnos de ambas. Tanto uma como outra se voltam ao estudo do outro, o ethnoi, por meio do contato direto e da interlocução com ele em sua vida cotidiana, para focalizar as práticas empregadas por esses atores sociais, na tentativa de desvendar os sentidos que atribuem a suas próprias ações.

A premissa central da etnometodologia repousa no pressuposto de que os agentes sociais são construtores dos processos de interação que se sucedem continuamente na vida cotidiana, e não meros reprodutores das regras que regem a normatividade social. Trata-se, assim, de uma ação reflexiva e interpretativa, tal como entendida por Garfinkel (1984). Essa compreensão foi fruto do amálgama que Garfinkel teceu com três referências fundamentais: as ideias de Parsons contidas em sua teoria da ação social, o interacionismo simbólico da Escola de Chicago e a fenomenologia de Schütz e Husserl. Para o sociólogo americano, o caráter ativo da ação social é o que permite aos agentes dar sentido a suas ações.

0 contato com os etnométodos permitiram a Coulon imprimir novos direcionamentos a suas pesquisas sobre a universidade e seus públicos, conforme conta em sua entrevista:

Então comecei uma grande pesquisa junto aos estudantes que ingressavam no primeiro ano, mas não obtive resultados verdadeiramente interessantes. Eu mesmo comecei voluntariamente a assumir unidade de ensino oferecida no primeiro ano. Comecei a fazer entrevistas com os estudantes que fracassavam, mas eles não tinham nada de interessante para dizer sobre seus fracassos. Diziam frequentemente que não estavam muito motivados, ou então que não tinham escolhido bem a área de formação ou ainda não entendiam de que lhes serviriam os estudos universitários. Desse modo, constatei a impotência da sociologia clássica da educação para explicar e compreender os fenômenos massivos de fracasso e abandono dos estudantes, em especial dos novos estudantes particularmente vulneráveis e frágeis. (p. 10-11).

A entrevista registrada neste número de Educação e Pesquisa, somada ao artigo "Le métier d'étudiant: l'entrée dans la vie universitaire", que exprime com lucidez teórica e competência sua trajetória no interior da sociologia francesa, oferece ao leitor um conjunto significativo de possibilidades que podem e devem ser exploradas para a formulação de novas perguntas para a pesquisa no interior da sociologia da educação e, mais especialmente, da sociologia do ensino superior.

Como afirma o autor, os problemas de adaptação aos estudos superiores são transnacionais e transgeracionais, afetam os países desenvolvidos e aqueles que, como o Brasil, iniciaram um processo de abertura de possibilidades de acesso que precisa ser intensificado ao lado de estudos e propostas que examinem os desafios da permanência. 


\section{Referências}

BECKER, Howard. Outsiders: etudes de sociologie de la déviance. Paris: A.-M. Métailié, 1985. Prefácio de Jean-Michel Chapoulie. BOURDIEU, Pierre. Esquisse d'une théorie de la pratique: précedé de trois études d'ethnologie kabyle. Paris: Seuil, 2000. Primeira edição em 1972.

BOURDIEU, Pierre. Le sens pratique. Paris: Minuit, 1980.

COULON, Alain. A Escola de Chicago. Tradução de Tomás R. Bueno. São Paulo: Papirus, 1995a.

COULON, Alain. Etnometodologia. Tradução de Ephraim Ferreira Alves. Petrópolis: Vozes, 1995c.

COULON, Alain. Etnometodologia e educação. Tradução de Guilherme João de Freitas Teixeira. Petrópolis: Vozes, 1995b.

COULON, Alain. Etnometodologia e educação. São Paulo: Cortez, 2017.

COULON, Alain. Le métier d'étudiant: approches ethnométhodologique et institutionnelle de l'entrée dans la vie universitaire. 1990. 3. v. 1130 p. Tese (Doutorado em Letras e Ciências Humanas) - Universidade de Paris 8, Paris, 1990.

GARFINKEL, Harold. Studies in Ethnometodology. Cambridge: Polity Press, 1984.

MATZA, David. Becoming Deviant. Englewood Cliffs: Prentice Hall, 1969. 


\section{Entrevista}

Tradução: Ana Teixeira

Sua trajetória intelectual no interior da sociologia francesa aponta para um percurso original e pioneiro. 0 que o levou a se interessar e a se envolver com a etnometodologia?

$\mathrm{Eu}$ faço parte de uma geração que começou os estudos universitários em meados dos anos 1960, uma época em que a sociologia ainda era uma disciplina pouco estudada na França. Eram poucos os departamentos de sociologia sobretudo nas universidades localizadas no interior do país. Digo isso porque fiz meus estudos na Universidade de Tours, onde o departamento de sociologia foi criado em 1965, ano anterior ao meu ingresso, por Jean Duvignaud, sociólogo, antropólogo, dramaturgo, romancista, cenógrafo, crítico de teatro e escritor em várias revistas. Em 1956 ele também fundou uma importante revista intitulada Arguments, com Edgard Morin e Kostas Axelos.

No primeiro ano, nós éramos apenas vinte estudantes matriculados em suas aulas (hoje são quinhentos nesse mesmo departamento de sociologia de Tours, o que é um absurdo em termos de possibilidades de emprego) e também nas aulas de George Lapassade, que tinha acabado de ser expulso da Tunísia, e Roger Establet, jovem assistente que tinha acabado de sair da Escola Normal Superior, em Paris.

Nós tínhamos aulas obrigatórias de filosofia, psicologia, história, demografia, etnologia, economia, inglês. Era um curso que correspondia, então, a uma formação muito completa em ciências humanas, indo da dinâmica de grupo até as contas da nação, passando pela análise institucional e a pedagogia não diretiva, muito cara para Georges Lapassade e em nome da qual ele nunca dava aulas, enquanto Roger Establet nos ensinava a fazer pesquisa de campo e construir quadros cruzando diferentes dados.

Ultrapassado o primeiro ano, quando nós não entendíamos quase nada, em especial durante as aulas de Jean Duvignaud, professor brilhante, que se dirigia a nós como se fossemos, com toda certeza, estudantes sociólogos, eu tive aulas muito interessantes, mesmo apaixonantes, com professores, em sua maior parte, surpreendentes e motivados. Fiz uma especialização em demografia, em psicologia, depois em sociologia da arte com Duvignaud.

Para mim, o primeiro ano na universidade é uma lembrança viva. Nessa época nós éramos menos de 20\% de uma geração a prosseguir os estudos até o ensino superior. Nós todos havíamos sido então bons alunos do ensino médio. Apesar disso, muito mais tarde, eu me questionei sobre por que o conjunto dos estudantes não compreendia nada das aulas de Jean Duvignaud. Essa questão permanecerá para mim como um questionamento heurístico, que reencontrei vinte anos depois como fio condutor de meu trabalho sobre a passagem entre o ensino médio e o ensino superior, que produz elevada taxas de fracasso entre os estudantes de primeiro ano.

Portanto, eu tive uma formação como sociólogo muito completa, ao mesmo tempo clássica, mas diversificada e original. No início dos anos 1970, eu comecei, com a concordância e apoio de Jean Duvignaud, uma tese dobre a sobrevivência da ideologia de pioneiro na Austrália. Depois de ter vivido na Austrália durante alguns meses eu abandonei essa ideia, pois não tinha encontrado meu tema em meu campo empírico.

Paralelamente a meus estudos, eu era vigilante de um internato de ensino médio, depois trabalhei em tempo parcial na clínica La Borde, um dos lugares fundadores da psicoterapia institucional, fundada por Jean Oury e Félix Guattari. Lá eu tive uma formação em psicanalise, teórica e prática, e acompanhava, também, as aulas de Lacan em Paris.

Em 1973, eu tive a ocasião de conseguir um posto como professor assistente de sociologia na Universidade de Argel. Fiquei nessa universidade durante quatro anos e fiz a minha primeira tese sobre a reforma do 
ensino superior na Argélia, sob a orientação de George Lapassade, antes de 1977 quando ingressei na Universidade de Paris 8, instalada, nessa época, no Bois de Vincennes, próximo de Paris. Era uma universidade muito inovadora, constantemente agitada, revolucionária sob vários aspectos, aberta para as novas correntes intelectuais e às ideias marginais.

A Universidade de Paris 8-Vincennes foi criada em dezembro de 1968, logo após os dias históricos de maio e junho de 1968, o que certos historiadores ou políticos chamaram de a revolução de 1968, que sacudiu várias democracias, por exemplo os Estados Unidos e a Alemanha, e que, na França, ganhou uma dimensão particular, pois não foram apenas os estudantes que se revoltaram, mas uma grande parte do país deflagrou uma longa greve geral em todos os setores de atividade.

Em resposta à movimentação dos estudantes que protestavam sobretudo contra a sociedade de consumo, o conservadorismo universitário e dos costumes em geral, o governo decidiu criar três universidade experimentais: uma em economia e gestão, em Paris 9-Dauphine (que ocupa as antigas instalações da Otan, em Paris), outra em ciências em Marseille-Lumigny, enfim, a terceira em letras e ciências humanas e sociais, em Paris, localizada no Bois de Vincennes, daí ter sido chamada durante muito tempo como Universidade de Vincennes.

Imediatamente após sua criação, a Universidade de Vincennes atraiu um grande número de intelectuais renomados, tais como Foucault, Deleuze, Lyotard, Châtelet, em filosofia, mas também em todas as outras disciplinas das ciências humanas e sociais. Em ciências da educação, Michel Debauvais, cofundador da Universidade, recruta Michel Lobrot, Jacques Ardoino, Guy Berger, na sequência chegam Georges Lapassade e René Lourau. Um departamento de informática também foi criado e viveu um grande sucesso durante muitas décadas, não somente em razão da qualidade de seus professores, mas, também, notadamente, porque suas salas equipadas com computadores ficavam abertas aos estudantes dia e noite, todos os dias do ano, com livre acesso tal como se via em algumas grandes universidades americanas.

Várias inovações importantes foram decididas e implantadas nessa nova universidade.

- Seria aceito o ingresso de estudantes

sem o baccalauréat ${ }^{2}$, bem como de trabalhadores que comprovassem três anos de trabalho assalariado. As mulheres que fossem responsáveis por criar uma criança de mais de 3 anos podiam, também, ingressar com todos os direitos assegurados, mesmo que não tivessem o baccalauréat.

- 0 ingresso de estudantes estrangeiros seria facilitado.

- A duração do curso para obtenção de um diploma de graduação permaneceria sendo de três anos, mas o ano universitário seria dividido em dois semestres de mesma duração.

- Para obter um diploma de graduação seria necessário acumular trinta créditos (unidades de ensino - UE), ou seja cinco por semestre, mas o ritmo de realização do curso seria escolhido por cada estudante.

- Esses créditos (UE) eram capitalizáveis, isso significava que um estudante não perdia as unidades obtidas e, em caso de necessidade (trabalho assalariado, interrupção dos estudos etc.), ele teria dez anos, no máximo, para concluir sua graduação.

- Em todas as áreas de conhecimento, a graduação estava organizada da mesma maneira. Para validar uma graduação, todo estudante deveria, obrigatoriamente, obter dezoito UEs na área de conhecimento escolhida como dominante, oito unidades em uma outra área, chamada subdominante e quatro unidades totalmente livres, que podiam ser cursadas em qualquer área oferecida pela universidade, seja na dominante ou na subdominante. Assim, essa organização inteligente permitia

2- Na França, o baccalauréat é um exame nacional que marca o fim do ensino médio. De modo geral ele equivale ao Enem no Brasil. A obtenção do baccalauréat (bac) é obrigatória para realizar a inscrição na universidade. Existem três grandes tipos de bac: o geral, o tecnológico e o profissional. 
instituir oficialmente para os estudantes o direito da dúvida, ou seja, o direito de errar na definição de uma área de concentração. Se o estudante fracassasse na área dominante ou simplesmente mudava de ideia era possível se reorientar em direção à área escolhida como subdominante. Assim, os numerosos estudantes que viviam essa situação não eram obrigados a recomeçar seus estudos desde o ponto inicial, pois podiam conservar certas UE que já tinham sido adquiridas e algumas vezes conseguiam assegurar todas as já cursadas.

- Ao longo dos três anos de graduação, em muitas áreas de conhecimento (exceto em línguas), os estudantes não eram separados pelo nível ou estágio em que se encontravam: eles eram voluntariamente misturados.

- Os cursos magistrais nos anfiteatros foram abolidos, e as aulas aconteceriam em pequenos grupos de aproximadamente vinte estudantes.

- Desde sua criação, a universidade estava equipada com uma excelente rede audiovisual interna que permitia transmitir as aulas e conferências em todas as salas de aula. Essa rede foi, infelizmente, rapidamente desmantelada, seja simplesmente por roubos, seja pela pilhagem de estudantes esquerdistas paranoicos que temiam que esse fosse um sistema de vigilância instalado pelo poder.

Durante vários anos, essa organização geral funcionou de maneira satisfatória. Algumas das inovações de Vincennes foram retomadas no plano nacional (por exemplo: unidades capitalizáveis, divisão do ano acadêmico em semestres), outras foram, progressivamente, abandonadas pela universidade ou desapareceram com a reforma universitária nacional de 1984. A normalização começava e o espirito de Vincennes desapareceu progressivamente à medida que uma outra sociedade nascia.

Durante um longo período, a Universidade de Vincennes foi o teatro de uma efervescência intelectual intensa com a presença continua de intelectuais importantes e prestigiados, frequentemente inovadores em suas disciplinas. Ela foi agitada quase que continuamente pelos debates políticos intensos e algumas vezes tempestuosos em que todos os grupelhos de extrema esquerda estavam representados. Apesar desses debates, a inovação intelectual estava presente em toda parte.

Como havia mencionado, eu cheguei à Vincennes em outubro de 1977, impressionado pelo entusiasmo e inteligência coletiva. Entretanto, rapidamente, eu me coloquei uma questão muito simples e, no meu ponto de vista, central, que não me parecia interessar, verdadeiramente, aos colegas que estavam muito comprometidos em suas atividades intelectuais engajadas: quais eram os reais resultados pedagógicos dos estudantes para além dos discursos políticos locais? Qual era a realidade dessa democratização do acesso ao saber, que era o estandarte da universidade desde sua criação?

Quando eu comecei a analisar esses resultados, descobri que era uma catástrofe: mais de 50\% dos estudantes inscritos não conseguiam conquistar nenhuma UE, mesmo quando os professores não eram muito severos e exigentes em suas avaliações! Estupefato, eu recomecei várias vezes os mesmos cálculos e chegava sempre às mesmas conclusões: não apenas menos da metade dos estudantes obtinha ao menos uma UE durante o ano acadêmico como, além disso, apenas 6\% dos estudantes tinham um percurso normal, ou seja, apenas 6\% obtinha dez UE ao longo de um ano acadêmico.

Quando eu quis apresentar esses resultados catastróficos ao mais alto nível da gestão da universidade eles me pediram que me calasse, pois isso poderia manchar a imagem da universidade. Esses resultados não deveriam ser divulgados, pois as subvenções atribuídas à universidade pelo Ministério eram, em grande parte, calculadas em função do número de estudantes inscritos. Nessa universidade que proclamava a liberdade acadêmica e reivindicava fortemente sua identidade de universidade inovadora em prol 
dos trabalhadores, a censura e a autocensura se instalaram, dissimuladas atrás da bela fachada politicamente correta.

Contudo, eu continuei, durante muitos anos, a analisar os resultados pedagógicos dos estudantes que eram sempre ruins. Tentei identificar os fatores objetivos para tentar explicar esse fenômeno. Mas todos os cruzamentos que eu pude efetuar não revelavam nenhuma diferença significativa entre os estudantes de tempo integral e os estudantes trabalhadores; entre os que tinham e os que não tinham o baccalauréat; entre os estudantes franceses e os numerosos estudantes estrangeiros. Todos fracassavam na mesma proporção.

Mas quando eu comecei a considerar apenas os estudantes do primeiro ano, obtive resultados espetacularmente significativos no plano estatístico. Quando os novos estudantes chegavam na universidade, os resultados eram verdadeiramente alarmantes: mais de 80\% fracassava totalmente, ou seja, não conseguia obter uma única UE ao longo do primeiro ano de estudos universitários!

Então comecei uma grande pesquisa junto aos estudantes que ingressavam no primeiro ano, mas não obtive resultados verdadeiramente interessantes. $\mathrm{Eu}$ mesmo comecei voluntariamente a assumir unidade de ensino oferecida no primeiro ano. Comecei a fazer entrevistas com os estudantes que fracassavam, mas eles não tinham nada de interessante para dizer sobre seus fracassos. Diziam frequentemente que não estavam muito motivados, ou então que não tinham escolhido bem a área de formação ou ainda não entendiam de que lhes serviriam os estudos universitários. Desse modo, constatei a impotência da sociologia clássica da educação para explicar e compreender os fenômenos massivos de fracasso e abandono dos estudantes, em especial dos novos estudantes particularmente vulneráveis e frágeis.

No final de 1984, no dia de Natal, eu lia o livro intitulado Power and Ideology in Education, e, no prefácio, encontrei, pela primeira vez, a expressão etnometodologia. Nessa época eu já tinha 37 anos!

Compreendi rapidamente do que se tratava, e descobri quais eram os principais autores dessa corrente cujo fundador é Harold Garfinkel. Fui a British Library em Londres, onde pude encontrar todos os documentos que não encontrei na França; depois, fui aos Estados Unidos, aos arquivos de Harvard, para ler a tese de Garfınkel. Em seguida, participei de um colóquio em Boston, durante o verão de 1987, onde encontrei o panteão internacional da etnometodologia. Foi quando Garfinkel me convidou para passar um período na UCLA como pesquisador e, então, em 1988, passei vários meses na UCLA estudando.

Essa descoberta da etnometodologia tinha me siderado: como um campo tão importante da sociologia americana, tão difundido em outros países de língua inglesa, podia ser tão profundamente ignorado pela sociologia francesa? Descobri que apenas alguns poucos filósofos e intelectuais, agrupados na École des Hautes Études en Sciences Sociales (EHESS) em torno de Louis Quéré, por exemplo, conheciam e se interessavam por essa corrente ao mesmo tempo que eu. Descobri, também, que sociólogos importantes como Pierre Bourdieu a conheciam, mas conheciam mal, com alguns contrassensos de interpretação, e tratavam do assunto em apenas algumas poucas linhas, frequentemente críticas e mesmo com desprezo. (Ver Bourdieu, Choses dites (1984), conferência proferida em San Diego, na presença de Cicourel, que o havia convidado).

$\mathrm{Na}$ verdade, a etnometodologia, assim como outras correntes sociológicas, tal como o interacionismo simbólico, foram sufocadas e desprezadas pelo marxismo estrutural que dominou as ciências sociais e humanas francesas entre os anos de 1950 e 1980, em particular nas publicações. Se a filosofia francesa sempre dedicou um bom lugar à fenomenologia (Merleau-Ponty, Sartre, Lefort), que influenciou de modo decisivo a etnometodologia, ela, durante muito tempo, refutou as abordagens centradas no sujeito, nas interações, nas ações 
sociais dos indivíduos. Isso explica o atraso com o qual a etnometodologia e as sociologias interacionistas conquistaram espaço na França. Contudo, o sucesso dessas abordagens foi considerável ao longo dos anos 1990. Atualmente, essas abordagens são pulsantes na França, mesmo que a etnometodologia já não se beneficie do forte efeito de moda que ela conheceu nos anos 1990 e 2000.

Com que tipo de grupos você tem trabalhado e quais lhe revelaram maior surpresa enquanto etnometodólogos?

Na UCLA, trabalhei com Garfinkel e pude acompanhar as últimas aulas de sua carreira em 1988, antes que ele fosse pressionado pela administração a solicitar sua aposentadoria aos 71 anos. Seu seminário se chamava $A$ Study of Norms. Incansavelmente, Garfinkel rendia suas homenagens à Durkheim e Parsons, transformando por dentro seus princípios teóricos e lhes revisitando com sua concepção etnometodológica.

$\mathrm{Eu}$ encontrava Garfinkel quase todos os dias na UCLA, sobretudo nas primeiras semanas de minha estada. Nós conversávamos frequentemente sobre a fenomenologia, em espacial sobre Merleau-Ponty, de quem ele admirava Le visible et l'invisible, escrito, como dizia Garfinkel, como se ele estivesse num estado de transe.

Desde a primeira semana de minha estada, eu lhe perguntava o que eram as lentes de inversão, sobre as quais eu havia ouvido falar na França. Ele me olhou sorridente e perguntou se eu queria verdadeiramente trabalhar com elas. Sem saber exatamente do que se tratava eu me arrisquei e respondi que sim. Tratava-se de grossos prismas montados em estruturas de borracha que impediam a visão lateral. Assim, quando olhávamos através desses prismas víamos a realidade invertida, o que está no alto aparece embaixo e o que está embaixo é visto no alto.

Quando se utilizava essas lentes, esses óculos, ficávamos imediatamente fora da realidade. Era uma experiência fenomenológica intensa e até mesmo violenta: todas as referências familiares desapareciam instantaneamente, a atitude natural, pela qual o mundo se apresenta em sua evidência, desaparece de imediato, nos sentimos perdidos nesse novo mundo, de cuja estranheza precisamos novamente nos apropriar. Com as lentes, era preciso reaprender tudo, inclusive operações simples, como escrever, enxergar, andar. $\mathrm{Na}$ verdade, andar pelo campus era um verdadeiro desafio, mesmo depois de um período de aprendizagem: as árvores vistas invertidas, ou seja, com a folhagem no chão pareciam obstáculos em que iríamos esbarrar!. Um outro exemplo: pegar um copo com água da torneira exigia muita atenção e uma reflexão lógica, em que os detalhes da ação apareciam em sua indispensável ordem cronológica, e o menor erro era imediatamente sancionado por uma mancha na camisa. Além disso, era verdadeiramente perigoso tentar subir ou descer escadas com as lentes no rosto.

As lentes permitiam, igualmente, ter acesso a fenômenos pouco conhecidos ou negligenciados da ação social e dos detalhes de sua realização. Assim, eu podia observar, simplesmente sentado em algum lugar do campus, como as pessoas andavam. Eu pude ver e descrever, em detalhe, em que consistia a caminhada individual, que tem pontos comuns, mas também singularidades segundo os indivíduos, e a caminhada coletiva, na qual os coparticipantes exibem fisicamente ao outro, pela sincronia de suas caminhadas individuais, que eles estão juntos, fenômeno muito importante na ação social pública.

Quando eu tirava as lentes, esses fenômenos desapareciam instantaneamente, mas a aprendizagem que eu tinha feito graças às lentes de inversão tinha me ensinado a competência da concentração necessária à observação e isso eu conservo até os dias de hoje.

Eu também encontrei e compartilhei muitas ideias com Jack $\mathrm{Katz}^{3}$, um dos

3- Jack Katz é autor de várias obras importantes, tais como Seductions of Crime ( New York: Basic Books, 1988) e How Emotions Work (Chicago: 
sociólogos qualitativos mais importantes dos Estados Unidos, que estudou com Howard Becker; também encontrei e compartilhei com Melvin Pollner, John Heritage, na UCLA; Don Zimmermann. em Santa Barbara; Hugh Mehan e Aaron Cicourel, em San Diego. Para mim essa foi uma experiência intelectual rara, um mergulho profundo que não seria possível conhecer nas ciências sociais na França, apesar de sua abertura progressiva nos anos de 1980.

Eu também me iniciei em análise da conversação seguindo o seminário de Emanuel Schegloff, que era um amigo fiel de Harvey Sacks, fundador dessa corrente, antes de sua morte prematura em 1975. Giolo Fele, atualmente professor na Universidade de Trento (Itália), também seguia esse seminário, que era, geralmente, frequentado por apenas três ou quatro estudantes. As aulas de Schegloff eram muito interessantes e precisas. Eu descobri a força analítica sociológica da análise da conversação. Àqueles que falavam de maneira crítica da análise da conversação, por ser uma microssociologia, Schegloff respondia com o exemplo das saudações, tanto as públicas como as que acontecem em particular, defendendo a ideia de que a sociedade cabe num grão de arroz. Segundo ele, todos os etnométodos utilizados por um grupo humano estão, em verdade, contidos nas simples saudações e na maneira de fazê-las.

Mais tarde, em 1991, encontrei Edward Rose em um colóquio em Amsterdã e, a partir de seu convite, fui para a Universidade do Colorado, em Boulder. Então, descobri que Rose podia ser considerado como o cofundador da etnometodologia em função das numerosas discussões e trocas de ideias que teve com Garfinkel e Sacks ao longo dos anos de 1960. Aprendi muito com ele, em particular que o mundo social é constantemente disponível ao olhar e à escuta do pesquisador e de todas as pessoas: o mundo se apresenta ele mesmo e

University of Chicago, 1999). Em breve, será publicada sua monumental história de Hollywood: Neighborhood Hollywood: Residential Community, Locally Shaped Biographies, and Cultural Representation, 1870-2010. se comenta sem parar diante de nós. 0 mundo social não existe fora de nós: somos nós que o coproduzimos e co-criamos sem parar. Esse fenômeno tem um nome: o mundo.

Em que momento houve uma definição de seu interesse pela investigação junto aos estudantes universitários?

Meu interesse por pesquisas concretas sobre os estudantes remonta a um momento muito anterior ao meu encontro com a etnometodologia. Eu mencionei que tinha feito minha primeira tese sobre a reforma do ensino superior na Argélia. Esse estudo sócio pedagógico tentou avaliar o impacto da reforma implantada em 1971 na Argélia, que tinha como objetivo formar os gestores de que o país precisava depois da independência conquistada em 1962. 0 contexto dos anos de 1970 na Argélia era de nacionalização dos hidrocarburantes e, de forma mais geral, de todas as indústrias: o Estado dirigia tudo. A reforma do ensino superior acontecia, então, num contexto revolucionário. Na época, existiam apenas três universidades na Argélia em Argel, Oran e Constantine -, que agrupavam um total de trinta mil estudantes. Em 2015, o país tinha cerca de cinquenta universidades e mais de cinquenta institutos superiores e grandes escolas. Esses estabelecimentos totalizam cerca de 1.600.000 estudantes.

Eu fui impactado desde a minha chegada em 1973 pela curiosidade e sede de aprender de meus estudantes, o que contrastava enormemente com aqueles que eu pude conhecer na França, frequentemente diletantes e pouco preocupados com o futuro profissional no contexto favorável da época. Na Argélia, os futuros diplomados sabiam que não teriam nenhum problema de emprego, mas, mesmo assim, trabalhavam muito, liam tudo que havia disponível, colocavam todo tempo questões de bom nivel durante as aulas que eu ministrava. Comecei a fazer pesquisas de campo com eles e a me interessar pelo sucesso e as dificuldades dos estudantes. 
Quando eu cheguei na Universidade de Vincennes, em 1977, como mencionei, descobri os resultados pedagógicos catastróficos dos estudantes nessa universidade, que se reivindicava como revolucionária com suas três variáveis sociológicas, que constituiam seu estandarte ideológico maior: os sem baccalauréat, os estrangeiros e os trabalhadores. Se a universidade de Vincennes foi a primeira a ser criada logo depois das manifestações estudantis de 1968 - e que logo recebeu o nome oficial de Paris 8, nos anos de 1970 - ela era a primeira universidade a aceitar estudantes sem o baccalauréat, bem como muitos estudantes estrangeiros (em certos anos essa proporção chegava a 40\%). Por outro lado, havia uma proporção importante de estudantes que trabalhavam ao mesmo tempo em que faziam seus estudos, com uma média de idade claramente superior à média nacional: 27,5 anos contra 21 anos da média nacional.

Somente com a minha descoberta da etnometodologia e da sociologia interacionista, pude me dar conta do que eu já sabia: a sociologia clássica da educação, chegando sempre depois do acontecimento que ela se propõe a estudar, descobre apenas coisas razoáveis e produz, na maior parte do tempo, resultados já conhecidos!

Ao contrário da etnometodologia e das sociologias interacionistas, a sociologia clássica da educação não permite ser testemunha dos fenômenos que ela adota como objeto de estudo. A partir de 1985, mudei mina abordagem sobre o fenômeno dos fracassos e dos abandonos dos estudantes de primeiro ano. Descobri in vivo, de maneira contemporânea a seus primeiros meses na universidade, como eles conseguiam se afiliar - ou não - a seu novo estatuto de estudante. Chamei essa aprendizagem intelectual de $o$ ofício de estudante. Acredito que pude, por abordagens e métodos diferentes - entrevistas, conversas, diários, observações - e sobretudo com uma teoria diferente como suporte, compreender como se tecem o sucesso ou o fracasso universitário. Esses trabalhos deram origem à minha segunda tese de Doutorado de
Estado em Letras e Ciências Humanas defendida em $1990^{4}$, com seu conceito central: afiliação.

Tem havido, no âmbito da etnometodologia, interesse pelo diálogo com a etnografia e a antropologia, uma vez que ambas se interessam pelo estudo do outro?

Mesmo que eu considere que a base teórica da etnometodologia é singular, única, poderosa e se basta em si mesma, ela comporta ligações evidentes com a etnografia e a antropologia, por conta da semelhança de métodos e técnicas de pesquisa. Tudo se caracteriza pelo trabalho de campo que as diferencia de outras abordagens mais clássicas em sociologia: elas todas se interessam pelo social em construção, o que não quer dizer, contrariamente ao que pretendem certas afırmações estúpidas, que elas ignorem a história ou as estratifıcações sociais, deixando de fora o social consolidado. Hoje penso que há uma unidade da sociologia apesar de sua diversidade. Continuo a me interessar intensamente pela abordagem estatística que revela, como dizia Bourdieu, as regularidades obstinadas.

Em algum momento a questão da cultura é útil para a etnometodogia? Ou essa abordagem prescinde desse conceito?

$\mathrm{Eu}$ considero que a questão da cultura é constantemente apresentada nos questionamentos etnometodológicos. Poderia mesmo afırmar que ela é constitutiva da abordagem etnometodológica. Os etnométodos que aprendemos, depois interiorizamos e utilizamos constantemente para viver juntos, e que são o corpus da pesquisa etnometodológica, constituem nossa cultura. Não a cultura nobre, à qual reduzimos frequentemente a cultura a história, a literatura, as artes, as ciências, a gastronomia etc. -, mas a cultura do senso comum, que se insinua em cada uma de nossas

4- COULON, Alain. Le métier d'étudiant: approches ethnométhodologique et institutionnelle de l'entrée dans la vie universitaire, 3 vol., 1130 p., 1990 Tese (Doutorado em Letras e Ciências Humanas) - Universidade de Paris 8. 
ações, que faz com que o outro nos reconheça imediatamente como um membro do mesmo grupo social. Nós todos possuímos - não somente os intelectuais - esse conhecimento íntimo e detalhado do funcionamento de nosso mundo social, que nos permite nele viver e ser reconhecido como membros competentes do mundo social em que todos nós vivemos. As pessoas sabem o que fazem, são racionais, elas não são, como assinala Harold Garfınkel, idiotas culturais com condutas impensadas.

Seu texto "Le métier d'étudiant" é muito interessante e oportuno para pensarmos em nossos estudantes, principalmente no momento de entrada na universidade. Segundo sua linha de raciocínio, ter competências (linguísticas e outras) é fundamental para a sobrevivência em um determinado meio social, e isso se aplica claramente aos jovens universitários que chegam ao mundo acadêmico. Que competências os jovens precisam adquirir para viver, e sobreviver, no meio acadêmico, hoje? Há diferenças geracionais na aquisição e na definição dessas competências diante dos processos de massificação do ensino e da heterogeneidade crescente do público universitário?

Incontestavelmente em inúmeros países, e não apenas nos países desenvolvidos, o acesso ao ensino superior se democratizou nos últimos vinte ou trinta anos. Mas se o acesso se tornou mais fácil do que era antes, os problemas de fracasso e abandono se tornaram, igualmente, maiores. A democratização abriu as portas do ensino superior para novos públicos pouco habituados à cultura universitária, com níveis heterogêneos e origens escolares diversificadas. A entrada difícil no que podemos chamar de cultura erudita é o outro lado da moeda da democratização.

0 que surpreendente é que os problemas de adaptação aos estudos superiores são transnacionais e transgeracionais. Encontramos o mesmo fenômeno em todos os países e em épocas diferentes. Poderíamos acreditar, por exemplo, que a chegada da internet na vida cotidiana, em particular para os jovens e estudantes, iria modificar profundamente a natureza do ensino e os modos de aprendizagem e melhorar sensivelmente os resultados escolares dos estudantes. Constatamos que não foi isso que aconteceu e que, ao contrário, muitas vezes, a abundância e facilidade para obter informações desorienta os estudantes fazendo-lhes crer que todo o saber está a um clique de distância! 0 trabalho intelectual é exigente e lento. Eu identifiquei duas competências essenciais, prévias a todo trabalho intelectual: por um lado a escrita e, por outro, a aprendizagem documental. São duas operações intelectuais poderosas, fáceis de se colocar em funcionamento em todas as universidades e que permitem aos novos estudantes, em particular, entrar em seu novo universo: o mundo das ideias.

Quando se refere ao métier d'étudiant, você considera apenas as competências intelectuais valorizadas pela universidade ou contempla também o uso de recursos de outra ordem, como a astúcia, a subserviência, o faz de conta?

As competências que eu acabo de indicar não são as únicas importantes, mas considero que elas são fundamentais e geradoras de outras práticas: compreensão das regras que toda aprendizagem subentende, formas de fazer, astucias práticas etc. É a esse conjunto de competências que eu chamei de ofício de estudante: ele não é adquirido em um único dia, mas certas práticas pedagógicas podem favorecer o acesso a ele. Eu diria que o ofício de estudante é adquirido de modo tanto mais rápido e duradouro quando o professor tem uma formação pedagógica, é paciente, mas também exigente. Não é rebaixando o nível de complexidade dos conteúdos e das exigências que resolveremos o problema do fracasso e do abandono no primeiro ano de estudos universitários, muito pelo contrário.

Os estudantes que eu conheço melhor são os franceses. Considero que eles não trabalham 
intelectualmente o suficiente. A maior parte procura - às vezes até mesmo reivindica - a facilidade, frequentemente antagonista da cultura científica exigida, em qualquer a área de estudo. Geralmente, seus professores não dizem que eles precisam trabalhar (estudar) mais, que às vezes é difícil e que é necessário se esforçar seriamente.

Uma de suas contribuições mais originais se situa no conceito de afiliação. Você considera que outras esferas da vida universitária, como a relação com o espaço público-político, as organizações e movimentos estudantis, as formas da sociabilidade entre os pares, podem também ser compreendidas a partir dessa categoria?

Podemos constatar, empiricamente, que o fato de os estudantes participarem de ações que não estão diretamente ligadas à sua aprendizagem acadêmica favorece o acesso a seu ofício: diferentes formas de sociabilidade no campus, atividades culturais, eventualmente militância estudantil, atividade beneficente. Sob condição de que isso não comprometa demasiadamente o tempo de estudo e de trabalho intelectual: a militância não substitui o esforço, a leitura dos textos originais, o exercício e as avaliações.

Sua defesa de uma pedagogia da afiliação é muito oportuna, sobretudo, sua proposta de um journal d'affiliation. Hoje observamos que os alunos têm outro tipo de relação com a escrita, aparentemente, um tipo de desinteresse decorrente da forte presença das tecnologias de informação e comunicação em todos os setores da vida contemporânea, que privilegiam a imagem e os textos enxutos. Você constata na França esse tipo de relação dos jovens com a escrita?

No meu ponto de vista, não são apenas as diferentes tecnologias da informação que seriam responsáveis pelo iletrismo relativo dos estudantes de hoje.É sem dúvida, essencialmente devido a seu despreparo no ensino médio: não se escreve muito no ensino médio! "É muito longo ler uma obra literária inteira”, então lemos extratos fotocopiados. "É muito difícil fazer um comentário sobre um texto”, então respondese apenas a questões fáceis. A mesma coisa para a matemática: não se resolvem problemas, fazem-se exercícios; hoje se considera que certas questões são muito difíceis inclusive na universidade, então o nível de exigência é reduzido pela modificação dos programas. Para 80\% dos alunos do ensino médio, a noção de esforço parece ter desaparecido. Não é, de jeito nenhum, uma questão relacionada ao número de alunos na sala de aula: por exemplo, na França, ao longo dos últimos trinta anos, o número médio de alunos por sala passou de 27 para 17 , e os resultados nunca foram tão ruins! A classificação dos alunos franceses no panorama internacional tornou-se preocupante e não é surpresa se muitos enfrentam dificuldade para ingressar na universidade.

É a catástrofe cultural do ensino médio, reforçada, em seguida, pelo acesso irrefletido à internet para procurar respostas simples para questões complexas, que induz uma grande parte a essas dificuldades. As redes sociais, que poderiam ser uma fonte fantástica de cultura e aprendizagem, são, ao contrário, marcadas pela busca de atividades lúdicas e ganhos financeiros.

Como você vê o intercâmbio com pesquisadores brasileiros no estudo dos estudantes universitários? Quais seriam os desafios para que essa interação seja fecunda?

Em maio de 2009, estive em Salvador, na Bahia, como diretor da Estratégia do Ensino Superior do ministério francês, a fim de representar o ministro do ensino superior para a comemoração dos trinta anos do Cofecub, colaboração exemplar entre o Brasil e a França ao nível do doutorado. Nós celebramos o fato de que, desde o início do acordo bilateral, mais de dois mil brasileiros, de todas as disciplinas, mas 
principalmente de áreas científicas e técnicas, tinham realizado sua formação doutoral na França, enquanto 160 jovens franceses tinham feito seus estudos no Brasil. Essa cooperação teve continuidade e até mesmo se ampliou a partir de 2011 com o Programa Ciências Sem Fronteiras, implementado pelo Brasil, implicando outros níveis de formação além do doutorado. Eu, pessoalmente, implantei esse programa durante o período em que cumpri a função de diretor da Estratégia e da Inserção
Profissional na direção do ministério até 2012, quando deixei o cargo. Podemos, certamente, lamentar que o Brasil tenha reservado esse programa exclusivamente para o domínio de áreas científicas e técnicas, e que não tenha, em seguida, incluído as ciências humanas e sociais.

É preciso continuar, ampliar a ação, multiplicar as parcerias: é uma cooperação eficaz, com baixos custos e muito benéfico para os dois países a longo prazo.

\section{Bibliografia do entrevistado}

COULON, Alain. Devenir enseignant du supérieur: enquête auprès des allocataires moniteurs de l'enseignement supérieur. Paris: L'Harmattan, 2004.

COULON, Alain. Ethnométhodologie et éducation. Paris: PUF, 1993. Em português: Etnometodologia e educação. Cortez: São Paulo, 2017. No prelo.

COULON, Alain. L’École de Chicago. Paris: PUF, 2016. Em português: A Escola de Chicago. Campinas: Papirus, 1995.

COULON, Alain. L'ethnométhodologie. Paris: PUF, 2014 Em português: A etnometodologia. Petrópolis: Vozes, 1995.

COULON, Alain. Le métier d'étudiant: l'entrée dans la vie universitaire. Paris: PUF, 2004. Em português: A condição de estudante: a entrada na vida universitária. Salvador: Edufba, 2016.

COULON, Alain. Les étudiants étrangers en France: l'état des savoirs. Rapport à l'Observatoire de la Vie Étudiante, mars 2003. Disponivel em: <http://www.ove-national.education.fr/medias/files/publications/b790_rapport_2e_phase.pdf >. Acesso em: ago. 2017.

COULON, Alain. Les taux de réussite en doctorat des allocataires de recherche financés par le Ministère de la Recherche. Rapport à la Mission Scientifique Technique et Pédagogique, Ministère de l'Enseignement Supérieur et de la Recherche, dez. 2003.

COULON, Alain. Note d'information de la direction de la prospective et du développement. Ministère de L'éducation Nationale. Les Allocataires Moniteurs de L'enseignement Supérieur, 03.10, février 2003. Disponível em: <ftp://trf.education.gouv.fr/pub/ edutel/dpd/ni0310.pdf>. Acesso em: ago. 2017.

COULON, Alain. Nouvelles approches dans la planification de l'enseignement supérieur. Enseignement Supérieur en Europe, Paris, v. 9, n. 1, 1984.

COULON, Alain. Penser, classer, catégoriser: l'efficacité de l'enseignement de méthodologie documentaire dans les premiers cycles. Le cas de l'université de Paris 8. Paris: Laboratoire de Recherche Ethnométhodologique: Université de Paris VIII, 1999.

COULON, Alain. Rapport sur L'état des Savoirs sur les Relations entre Enseignants, Étudiants, et Personnels Administratifs dans L'enseignement Supérieur Français, OVE, jun. 2008. Disponível em: <http://www.ove-national.education.fr/medias/files/ publications/Rapport_OVE_-_Coulon-Paivandi.pdf>. Acesso em: 15 ago. 2017.

COULON, Alain. Universités: un état des lieux. [s. L.: s. n.], 1983. (Troisième millénaire; 11.)

COULON, Alain; BERGER, Guy; Catz, Tania. L'innovation dans l'enseignement supérieur. Paris: Unesco. Division de l'Enseignement Supérieur, $1982,150 \mathrm{p}$.

COULON, Alain; DESMAZIERES, Danièle; POITEVIN, Christine. Apprendre à s'informer: une nécessité. Évaluation des formations à l'usage de l'information dans les universités et grandes écoles françaises. Paris: Laboratoire de Recherche Ethnométhodologique. Université de Paris VIII, 1999. 114 p. 